\title{
MoMo: a new empirical model of the Mars ionospheric total electron content based on Mars Express MARSIS data
}

\author{
Nicolas Bergeot ${ }^{1,2,3, *}$, Olivier Witasse ${ }^{4}$, Sébastien Le Maistre ${ }^{2}$, Pierre-Louis Blelly ${ }^{5}$, Wlodek Kofman ${ }^{6,7}$, \\ Kerstin Peter $^{8}$, Véronique Dehant ${ }^{2,3}$, and Jean-Marie Chevalier ${ }^{1,2}$ \\ ${ }^{1}$ Solar-Terrestrial Centre of Excellence (STCE), Space Pole, 1180 Brussels, Belgium \\ ${ }^{2}$ Royal Observatory of Belgium Brussels, 1180 Uccle, Belgium \\ ${ }^{3}$ Earth and Climate, Université Catholique de Louvain, 1348 Louvain-la-Neuve, Belgium \\ ${ }_{5}^{4}$ European Space Agency, ESTEC-Scientific Support Office, ESTEC, 2201 AZ Noordwijk, The Netherlands \\ ${ }^{5}$ Institut de Recherche en Astrophysique et Planétologie (IRAP), 31400 Toulouse, France \\ ${ }^{6}$ Université Grenoble Alpes, CNRS, CNES, IPAG, 38400 Grenoble, France \\ ${ }^{7}$ Space Research Centre, PAS, 00716 Warsaw, Poland \\ 8 Rheinisches Institut für Umweltforschung an der Universität zu Köln, Abt. Planetenforschung, 50931 Köln, Germany
}

Received 27 February 2019 / Accepted 9 September 2019

\begin{abstract}
Aims: Several scientific landers and rovers have reached the Martian surface since the 1970s. Communication between the asset (i.e., lander or rover) and Mars orbiters or Earth antennas uses radio signals in UHF to X-band frequencies passing through the Mars' ionosphere. It is consequently necessary to take into account electron density variation in the Mars' ionosphere to correct the refraction of the signal transmitted.

Methods: We developed a new empirical model of the Mars' ionosphere called MoMo. It is based on the large database of Total Electron Content (TEC) derived from the subsurface mode of the Mars Express MARSIS radar. The model provides vertical TEC as a function of solar zenith angle, solar activity, solar longitude and location. For validation, the model is compared with Mars Express radio occultation data as well as with the numerical model IPIM (IRAP Plasmasphere-Ionosphere Model).

Results: We discussed the output of the model in terms of climatology behaviour of the Mars' ionosphere. The output of MoMo is then uses to quantify the impact of the Martian ionosphere for radio-science experiments. From our results, the effect is of the order of $10^{-3} \mathrm{~mm} \mathrm{~s}^{-1}$ in Doppler observables especially around sunrise and sunset. Consequently, this new model could be used to support the data analysis of any radio-science experiment and especially for present InSight RISE and futur ExoMars LARA instruments aiming at better understand the deep-interior of Mars.
\end{abstract}

\section{Introduction}

Radio-science experiments are used to obtain motions of spacecraft or asset (e.g., lander and rover) around or on planets or moons in space. One usually performs Doppler measurements alone on the radio signal between the Earth and the asset in order to reconstruct its position and velocity variations. Ranging is also used for obtaining ephemerides of planets or moons. For a spacecraft or asset on its surface at Mars, dedicated radio frequency bands for space communications are determined by the International Telecommunication Union (ITU). The frequencies used are in UHF (0.3-3.0 GHz), S-band $(2.0-4.0 \mathrm{GHz}), \mathrm{X}$-band $(8.0-12.0 \mathrm{GHz})$, and in the future, Ka-band $(26.5-40 \mathrm{GHz})$. At present most of the spacecraft

\footnotetext{
*Corresponding author: nicolas. bergeot@oma. be
}

use UHF for inter-satellite links and X-band for Earth-Mars links. Previously, landers such as Viking and or Pathfinder used S-band.

Concerning recent and future missions, the NASA lander InSight (Interior Exploration using Seismic Investigations, Geodesy and Heat Transport), which landed successfully in November 2018, conducts a radio-science experiment called RISE (Rotation and Interior Structure Experiment, Folkner et al., 2018). The lander signal in X-band is routinely tracked from Earth, with the goal of measuring the rotational movements of the red planet, in order to study its deep interior. A very similar and complementary radio-science experiment called LaRa (Lander Radio science, Dehant et al., 2009, 2011, 2019), was also designed to refine the rotation model of Mars and to further constrain its interior. LaRa is part of the scientific payload of the Russian surface platform of the 
ESA-Roscosmos ExoMars 2020 mission. The X-band measurements provided by these two missions have unprecedented accuracy (and low power level in the case of LaRa). In particular, at least centimeter accuracy in the position determined from the phase delay is required. Doppler measurements from RISE and LaRa instruments are at a precision as high as $0.02 \mathrm{~mm} \mathrm{~s}^{-1}$ at $60 \mathrm{~s}$ integration time corresponding to the instrument precision requirement. However, the impact of a liquid core on Martian Orientation Parameters is lower than $0.004 \mathrm{~mm} \mathrm{~s}^{-1}$ in X-band (Yseboodt et al., 2017) and could be detected from data time-series. To reach this accuracy, the ionospheres of Mars and Earth as well as the interplanetary plasma contributions need to be corrected for along the line of sight. Because the ionosphere and plasma effects depend on frequency, an adequate combination of radio signals on two frequencies allows scientists to obtain corrected radio links (see Mars Express radio science experiment in Pätzold et al., 2004). However, landers have usually only one frequency disabling the correction for these effects. This is also the case for the radio-science experiments RISE and Lara which use only one S-band frequency. It is thus important to take into account the ionospheric effect on radio signals using external models to correct for ionospheric and plasma effects.

Ionosphere effects for the Earth can be modelled from, e.g., GNSS observations (e.g., Klobuchar et al., 1996) and are nowadays well corrected for most radio-wave based applications. Solar plasma is another source of degradation of the radioscience data quality. Pretty low when Mars elongation is above $\sim 15^{\circ}$, the solar plasma noise strongly increases for smaller angles. Data acquired close to solar conjunctions are usually excluded from radio-science analysis or they are properly weighted (e.g., Zuber et al., 2007) when combined with data acquired at larger angle. Concerning the Mars' ionosphere, several models exist. Let us cite the IPIM model (IRAP Plasmasphere-Ionosphere Model, Marchaudon \& Blelly, 2015), a state of the art numerical model, which is heavy to run for routine processes. Another existing model is the recent empirical model called NeMars (Sánchez-Cano et al., 2013) constructed from MARSIS data. This model is based on data from a special mode of the Mars Express radar (active ionospheric sounding), which does not probe the entire ionospheric layer (Sánchez-Cano et al., 2012; Morgan et al., 2013). Peter et al. (2014) published a 1-dimensional model of the ionosphere, used to interpret the Mars Express radio-occultation data. Recently, the Mars International Reference Ionosphere (MIRI-2018, Mendillo et al., 2018) provides a new module for Total Electron Content (TEC) using more than 120,000 values from the Mars Reconnaissance Orbiter/SHAllow RADar (MRO/SHARAD). The TEC output available on the web (http://sirius.bu.edu/miri/miri.php) is driven by Solar Zenith Angle (SZA) and solar index only. The output TEC is the integrated value for the electron density for altitudes comprise between 80 and $270 \mathrm{~km}$ while the ionopause (i.e., upper limit of the ionospheric plasma) is generally considered to be more than $400 \mathrm{~km}$ (e.g., Morel et al., 2004).

The aim of the present paper is to provide a new model of the Mars' ionosphere with few coefficients, simple to use but taking into account for areophysical considerations (i.e., absorption of the solar EUV in a terrestrial atmosphere, seasons, hemispheric dichotomies) and adapted to correct data for any experiment using radio signals. In order to build such tool, we used existing radar data derived from Mars Express TEC measurements between the surface up to $900 \mathrm{~km}$. Our model is called model of Mars' ionosphere (MoMo) and can be used to predict the Martian ionospheric TEC in a simple way. The goal is to provide corrections to be applied for any investigations using radio signal probing the Mars' ionosphere at a given location, at a given time and for a given solar activity level.

The first section of the paper describes the data used to build our model, the model itself and the validation of our approach with independent radio occultation data and the IPIM model. The second section describes the climatology behaviour of the Mars' ionosphere using our model, and provides some applications to radio-science experiments.

\section{Data and model}

This section is divided in three sub-sections. First we describe the MARSIS data used. Secondly, we describe the strategies and equations used to build the model and finally we validate the model for different SZA and solar activity levels.

\subsection{Data and method}

We analysed the ionospheric data from 6,870,739 echoes (6850 tracks) from the Mars Advanced Radar for Subsurface and Ionospheric Sounding (MARSIS) radar sounder in subsurface mode. The data set consists of vertical Total Electron Content (vTEC, i.e., the vertical integral of the electron density from the satellite to the ground, expressed in TEC units with $1 \mathrm{TECu}=10^{16} \mathrm{e}^{-} \mathrm{m}^{-2}$ ) for the period 19-06-2005 to 01-022014 (Safaeinili et al., 2007; Mouginot et al., 2008). Only data with acceptable signal to noise ratio threshold (i.e., SNR is greater than $15 \mathrm{~dB}$, Grima \& Kofman, 2008) where used. The data from year 2005 were also excluded after quality visual check (i.e., too much noisy and unrealistic vTEC values). Finally, the data set used consists of 5,308,594 echoes (more than $75 \%$ of the entire data set). The main limitation is that the MARSIS radar sounder in subsurface mode operates primarily at SZA higher than $60^{\circ}$. Indeed, although the SZA of the whole data set varies between $4^{\circ}$ and $171^{\circ}$, a large part of the measurements $(\sim 85 \%)$ are acquired between $60^{\circ}$ and $120^{\circ}$ around the solar terminator (i.e., when $\mathrm{SZA} \approx 108^{\circ}$ ). Sánchez-Cano et al. (2015) carried out a critical analysis of different vTEC data sets and processing techniques and recommend to consider an error bar between 0.3 and 1 TECu for SZA lower than $75^{\circ}$. Thus, we paid attention to validate our model at different ranges of SZA.

The first driver used to model the variation of the vTEC is the EUV emission from the Sun accounting for the photoionization for a given solar activity level. The index widely used to model the vTEC on Earth is the daily integrated emission from the solar disc at $2800 \mathrm{MHz}(10.7 \mathrm{~cm}$ wavelength called F10.7) recorded routinely since 1947 (Covington, 1969) for 1 AU distance. The F10.7 is expressed in solar flux unit (sfu, with $1 \mathrm{sfu}=10^{-22} \mathrm{Wm}^{-2} \mathrm{~Hz}^{-1}$ ). Nowadays, an additional index called F10.7P (i.e., the mean of daily F10.7 of the day of interest and its average over the previous 81 days), is considered as the new proxy which better represents the solar EUV 


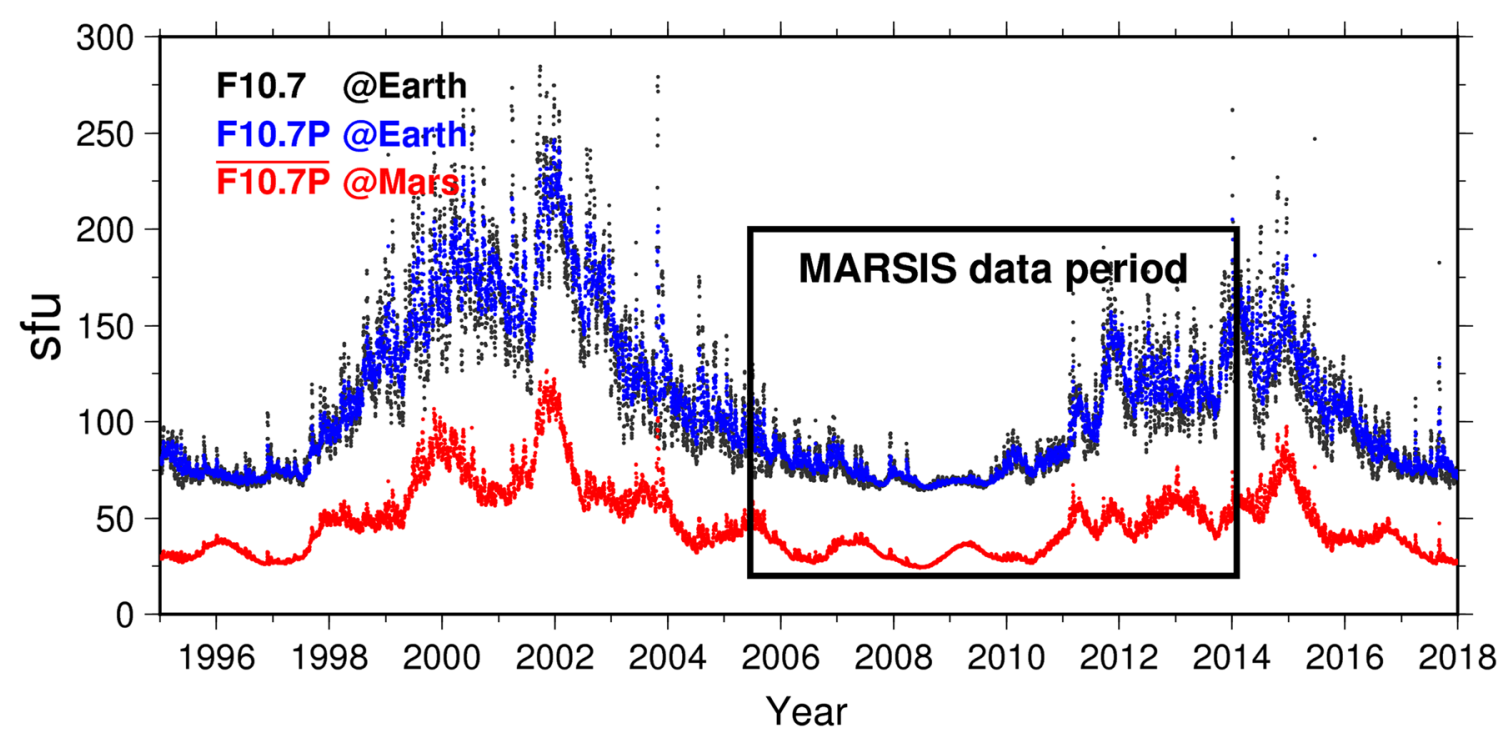

Fig. 1. Daily solar indices during the 23rd and 24th solar cycles in Solar Flux Unit (sfu). Daily F10.7 flux from Penticton radio telescope observations (black) and derived F10.7P (blue). The red dots are the $\overline{\text { F10.7P }}$ used for Mars. The black box represents the MARSIS data period used in this study.

fluxes causing the photo-ionisation of the Earth neutral atmosphere when comparing with satellite SEM/SOHO EUV data (Liu et al., 2006). While this new index is nowadays used to predict the Earth ionosphere activity (Liu \& Chen, 2009; Bilitza et al., 2011; Bergeot et al., 2013), the Mars' ionosphere is generally studied using the F10.7 (Lillis et al., 2010; Mendillo et al., 2013) corresponding to F10.7 corrected from the Sun to the Mars distance $\left(d_{\mathrm{S}-\mathrm{M}}\right)$ and defined as $\overline{\mathrm{F} 10.7}=\frac{F 10.7}{d_{S-M}^{2}}$. The $\overline{\text { F10.7P }}$ (Fig. 1) is used in this study as index to describe the solar EUV emission at Mars. Starting from the F10.7 from the Penticton radio telescope, we derive the $\overline{\mathrm{F} 10.7 \mathrm{P}}$ using the relation:

$$
\overline{\mathrm{F} 10.7 \mathrm{P}}=\frac{\overline{\mathrm{F} 10.7}+\overline{\mathrm{F} 10.7 \mathrm{~A}}}{2},
$$

where $\overline{\mathrm{F} 10.7 \mathrm{~A}}$ is the 81 -previous days mean of daily $\overline{\mathrm{F} 10.7}$.

We made some tests taking into account for the time taken for the Sun to rotate from facing Earth to facing Mars. This delay, which varies between -14 and +14 days depending on the configuration, has a negligible effect on the resulting

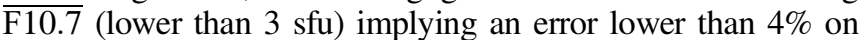
the output of our model. Thus, for more simplicity, we neglected this time delay/advance to estimate the $\overline{\text { F10.7 }}$ as it is more simple for potential users of our model.

For the period of MARSIS data used in this study (see Fig. 1), the F10.7P (resp. $\overline{\mathrm{F} 10.7 \mathrm{P}}$ ) ranges from $65 \mathrm{sfu}$ (resp. $24 \mathrm{sfu}$ ) to $205 \mathrm{sfu}$ (resp. $77 \mathrm{sfu}$ ). Therefore, we considered in the present study a F10.7P (i.e., at 1 AU) of 70 sfu for low, $120 \mathrm{sfu}$ for moderate and $170 \mathrm{sfu}$ for high solar activity levels.

The other parameter taken into account for our model is the Solar Longitude (Ls), which characterises the position of the planet around the Sun, and thus the seasons. Regarding the repartition time and space domain with respect to Ls, SZA and $\overline{\text { F10.7P }}$ of the MARSIS data set, two different sets of Ls are considered: from mid-spring to mid-autumn comprising the summer ( $\mathrm{Ls}$ in $\left.\left[45^{\circ} ; 225^{\circ}\right]\right)$ and from mid-autumn to mid-summer comprising the winter season (Ls in $\left[225^{\circ} ; 45^{\circ}\right]$ ) in the Northern hemisphere. This allows taking into account the variations in the thermospheric reservoir (for the ionosphere) between summer and winter.

The last parameter considered is the inter-hemispheric dichotomy of Mars. To highlight the general distribution of the vTEC on Mars, the mean of the vTEC values for SZA lower than $75^{\circ}$ for the entire period (2006-2014) on a $10^{\circ} \times 10^{\circ}$ grid is shown in Figure 2.

There is a clear dichotomy between the Northern and Southern vTEC general level, with higher vTEC values in the South ( 0.6 TECu; Min: 0.4 TECu; Max: 0.8 TECu) compared to the North $(\sim 0.5 \mathrm{TECu}$; Min: $0.4 \mathrm{TECu}$; Max: 0.6 TECu). Additionally, the standard deviation of the distribution (top left Fig. 2) is higher at low latitudes (i.e., close to the equator) compared to mid- and high latitudes. This indicates a relative stability of the mean vTEC at high latitudes and consequently the reliability of higher values in the Southern hemisphere compared to the North. This is due to the effects on the ionosphere of the crustal magnetic field (e.g., Flynn et al., 2017) which are stronger in the southern hemisphere (Acuña et al., 2001). To support our conclusion on the hemispherical dichotomy, we also considered the mean for the SZA and the $\overline{\mathrm{F} 10.7 \mathrm{P}}$ (Figure 2 middle and right). From the global mean repartition of these quantities, there is no clear dependence of the mean vTEC with respect to the SZA and $\overline{\text { F10.7P }}$ neither latitude nor longitude. In our model, we take into consideration this dichotomy by analysing separately the Northern and the Southern hemispheres.

\subsection{Empirical model of Mars' ionosphere}

The main driver of the evolution of the vTEC at a given location is the solar radiation whose penetration in the atmosphere depends on the SZA. The SZA as the main parameter to constrain the model. In order to fill lack of data at low SZA, we considered the formulation for the Chapman grazing 

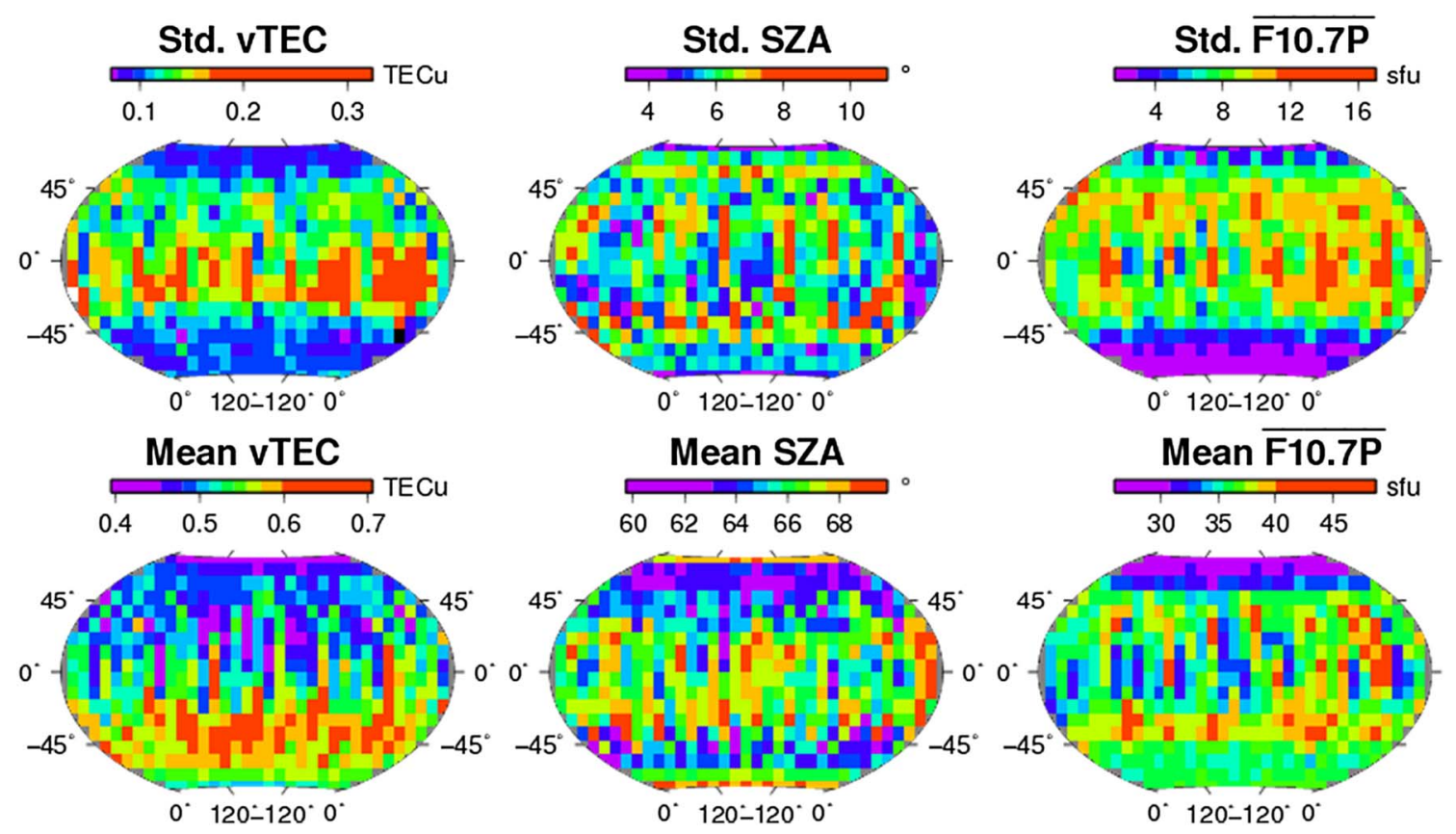

Fig. 2. vTEC, SZA and $\overline{\mathrm{F} 10.7 \mathrm{P}}$ distribution on Mars for SZA lower than $75^{\circ}$. Bottom: mean values every $10^{\circ}$ in longitude and latitude for the entire period (2006-2014) for vTEC (left), SZA (middle) and $\overline{\text { F10.7P }}$ (right). Top: standard deviation of the mean at $1 \sigma$.

incidence integral noted $\boldsymbol{c h}\left(X_{p}, \mathrm{SZA}\right)$. The use of this function allows the determination of the absorption of the solar EUV in a terrestrial atmosphere, and consequently the ionisation rate, over a wide range of solar illuminations (Chapman, 1931). The simplified function is given by (Eq. 9 in Smith \& Smith, 1972):

$$
\boldsymbol{c h}\left(X_{p}, \mathrm{SZA}\right)=\sqrt{\frac{\pi}{2} X_{p}} \times f(\mathrm{SZA})
$$

where $X_{p}$ is the distance of the estimated ionospheric thin shell layer with respect to the centre of Mars $(3392+140 \mathrm{~km})$ divided by the atmospheric scale height $(\sim 15 \mathrm{~km})$, SZA the Solar Zenith Angle and $f($ SZA) the functions defined in Smith $\&$ Smith, 1972. Using this formulation, the function is divided in two ranges of SZA: SZA $\leq 90^{\circ}$ (see Eq. (12) in Smith \& Smith, 1972) and SZA $>90^{\circ}$ (see Eq. 15 in the same reference). The use of this formulation allows us to extrapolate the model for SZA lower than $60^{\circ}$ where there is a lack of data, taking into account for the physical processes defined in Chapman (1931) to describe the absorption of Solar radiation in a planetary atmosphere.

Among all the tests we made, our best theoretical vTEC (in terms of differences between the predicted values and the data in input) is modelled according to:

$$
\operatorname{vTEC}(\mathrm{SZA}, \mathrm{Hem}, \mathrm{Ls}, \overline{\mathrm{F} 10.7 \mathrm{P}})=\alpha_{1}+\frac{\alpha_{2}}{\sqrt{\boldsymbol{c h}\left(X_{p}, \mathrm{SZA}\right)}},
$$

where $\boldsymbol{c h}\left(X_{\mathrm{p}}, \mathrm{SZA}\right)$ is the function given in equation (2), $\alpha_{1}$ and $\alpha_{2}$ coefficients are parameters estimated to fit the observations by minimizing the squared differences between the modelled and observed vTEC from MARSIS data in a least-square sense.
At this stage, the vTEC is predicted for a given range of $\overline{\text { F10.7P }}$ index taking into account for the heliocentric distance of Mars (see Eq. (1), at a given SZA, in a given hemisphere $(\mathrm{Hem})$ and for a given Ls range $\left(\mathrm{Ls}=\left[45^{\circ} ; 225^{\circ}\right]\right.$ or Ls $\left.=\left[225^{\circ} ; 45^{\circ}\right]\right)$. For that, different tools and data from SPICE/NAIF (Acton, 1996; Acton et al., 2018) were used to retrieve information such as solar longitude, heliocentric distance or SZA at a given location and time.

Figure 3 shows the estimated $\alpha_{1}$ and $\alpha_{2}$ coefficients for (1) each hemisphere, (2) for the two Ls ranges defined above and (3) for different ranges of $\overline{\mathrm{F} 10.7 \mathrm{P}}$ (from 20 to $80 \mathrm{sfu}$ with a step of $5 \mathrm{sfu}$ ).

As first order approximation, the $\alpha_{1}$ coefficients can be considered as constant with respect to the $\overline{\mathrm{F} 10.7 \mathrm{P}}$ (see Fig. 3 left panels), while the $\alpha_{2}$ coefficients are linearly dependent on F10.7P (see Fig. 3 right panels). Therefore, to make MoMo applicable for any solar activity level and heliocentric distance, equation (3) is refined as follows:

$$
\begin{aligned}
& \mathrm{TEC}(\mathrm{SZA}, \text { Hem, Ls, } \overline{\mathrm{F} 10.7 \mathrm{P}}) \\
& =\operatorname{mean}\left(\alpha_{1}\right)+\frac{\beta_{1}+\beta_{2} \times \overline{\mathrm{F} 10.7 \mathrm{P}}}{\sqrt{\operatorname{ch}\left(X_{p}, \mathrm{SZA}\right)}},
\end{aligned}
$$

where mean $\left(\alpha_{1}\right)$ is the mean of the $\alpha_{1}$ and $\alpha_{2}$ is replaced by a linear equation parameterised by $\beta_{1}$ and $\beta_{2}$ and defined as $\alpha_{2}=\beta_{1}+\beta_{2} \times \overline{\mathrm{F} 10.7 \mathrm{P}}$.

Finally, MoMo consists of 12 coefficients: three coefficients for each hemisphere and solar longitude range. The mean of the differences between the model and the observations is $0.01 \pm 0.06 \mathrm{TECu}$ (Figure 4) with only $\sim 9 \%$ of the absolute value of differences larger than 0.1 TECu between MoMo outputs and MARSIS observations. The coefficients to be used in 

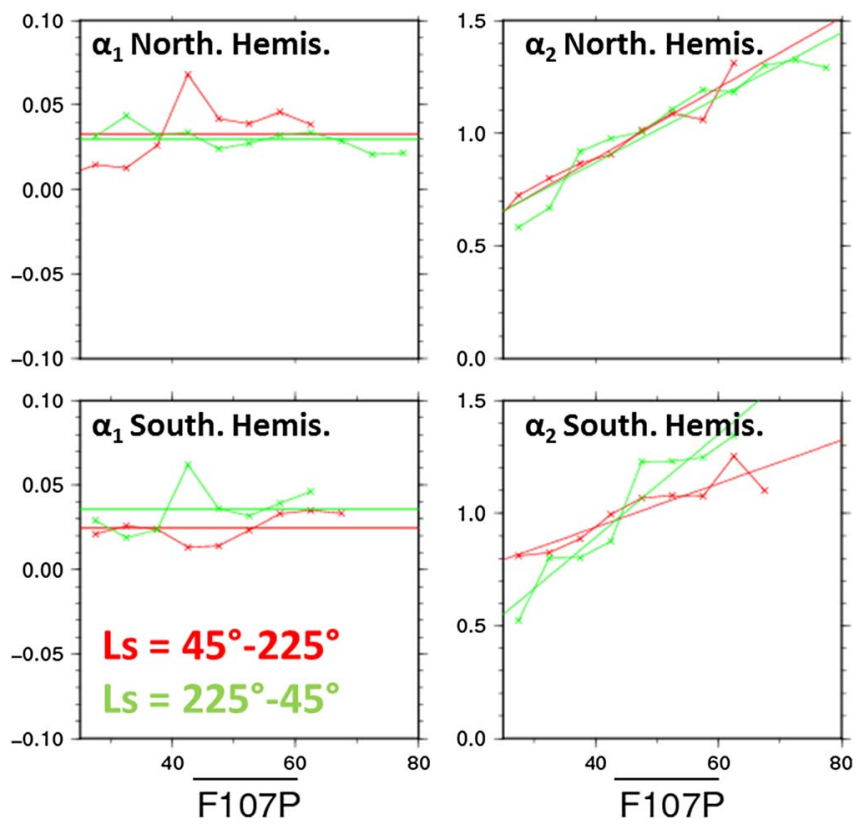

Fig. 3. Coefficients $\alpha_{1}$ and $\alpha_{2}$ estimated from the least-square adjustment of equation (3). Top: for the Northern hemisphere; Bottom: for the Southern hemisphere. The colours are related to the Martian seasons with $45^{\circ} \leq \mathrm{Ls}<225^{\circ}$ for the red curve and $225^{\circ} \leq \mathrm{Ls}$ $<45^{\circ}$ for the green curve. The lines are the estimated $\alpha_{1}$ and $\alpha_{2}$ coefficients with respect to the $\overline{\mathrm{F} 10.7 \mathrm{P}}$. The crosses are the coefficients obtained for the different $\overline{\mathrm{F} 10.7 \mathrm{P}}$ index while the lines are the values used in the model.

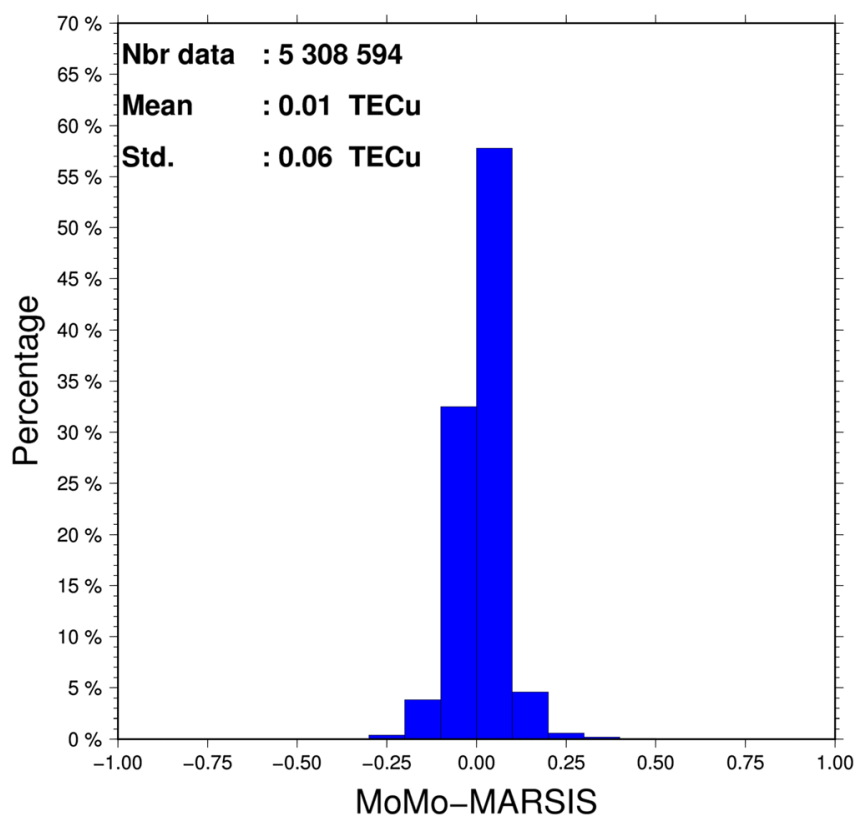

Fig. 4. Histograms of the differences between MoMo output and MARSIS data set used to constrain the model.

equation (4) and the RMS of the model are available in Table 1. The model (subroutine sub_momo.f) and the $\overline{\mathrm{F} 10.7 \mathrm{P}}$ index are available at https://lara.oma.be/marsatmo/iono/momo.html.

\subsection{MoMo model validation}

To validate the model, the output from MoMo is compared with a completely independent data set, consisting of 250 electron density profiles of the dayside ionosphere (SZA $\left[50^{\circ}-85^{\circ}\right]$ ) extracted from Mars Express radio occultation experiments MaRs (Peter et al., 2014). The mean differences between MoMo and MaRs data is $0.01 \pm 0.05 \mathrm{TECu}$ for SZA greater than $50^{\circ}$ (Fig. 5), which is as the same level as the differences with MARSIS data. The mean of the differences in the North is $0.00 \pm 0.04 \mathrm{TECu}$, while the differences in the South are $0.03 \pm 0.06 \mathrm{TECu}$. This could be due to more intense ionospheric variability in the South not well represented in MoMo which aims at representing the climatology of the vTEC. Furthermore, these differences are lower than $10 \%$ of the vTEC values. Consequently, our model reflects well the dayside ionosphere vTEC especially for mid- to low- solar elevations (i.e., larger than $50^{\circ}$ of SZA).

MoMo is also compared with the IPIM numerical model (Marchaudon \& Blelly, 2015) which includes physical processes in the ionosphere (e.g., electrodynamics, energetics, transport, photo-chemistry, etc). One of the outputs of this model are the density profiles which we integrated with respect to the altitude to compare with MoMo runs (Fig. 6). We consider here three runs for IPIM: case 1 corresponding to location in the Southern hemisphere during Northern Winter and low solar activity $(22-06-2009, \mathrm{~F} 10.7=70$ sfu, i.e., $\overline{\mathrm{F} 10.7 \mathrm{P}}=$ 34.8 sfu, latitude $=45^{\circ} \mathrm{S}, \mathrm{Ls}=289.6^{\circ}$ ); case 2 for a location in the Northern hemisphere during Northern Spring and intermediate solar activity (18-08-2013, F10.7 = 129 sfu; $\overline{\mathrm{F} 10.7 \mathrm{P}}=47.9 \mathrm{sfu}$, latitude $\left.=45^{\circ} \mathrm{N}, \mathrm{Ls}=8.6^{\circ}\right)$; case 3 for a location in the Northern hemisphere during Northern Autumn and intermediate solar activity (24-10-2012, F10.7 = $129 \mathrm{sfu}$; $\overline{\mathrm{F} 10.7 \mathrm{P}}=61.8 \mathrm{sfu}$, latitude $=20^{\circ} \mathrm{N}, \mathrm{Ls}=194.0^{\circ}$ ).

The shapes of the vTEC values of the two models are very consistent with differences between -0.12 and $0.06 \mathrm{TECu}$ (mean of $0.01 \pm 0.03 \mathrm{TECu}$ ) showing the efficiency of the MoMo estimations even at low SZA. Despite MoMo's simplicity, the behaviour of the Mars' ionosphere is well predicted. This comforts us in the reliability of MoMo outputs even at low SZA. Presently, no data are available for SZA lower than $30^{\circ}$. This is the reason why we considered physical model (Smith \& Smith, 1972) to extrapolate our vTEC at low SZA. In the future, satellites data with SZA $=0^{\circ}$ will be necessary to validate MoMo and all the models available.

\section{Model applications}

In this second section, MoMo outputs are used for different applications. The first sub-section is dedicated to the climatology of the Mars' ionosphere while the second sub-section deals with the impact of the Mars TEC on radio-science experiments.

\section{1 vTEC climatology on Mars}

To access the climatological behaviour of the Martian ionospheric, MoMo is used to predict the Martian vTEC for different seasons, hemispheres and solar activity levels. Figure 7 presents the daily variations (for $0^{\circ} \leq \mathrm{SZA} \leq 110^{\circ}$ ) of the 
Table 1. Coefficients for the MoMo model to predict the vTEC in the Mars' ionosphere. These coefficients are given for different ranges of solar longitude (Ls) and the two hemispheres. The number of data per range of SZA and the associated RMS of the differences between the vTEC predicted by the model and the observed vTEC are reported in the last columns.

\begin{tabular}{|c|c|c|c|c|c|c|c|c|}
\hline & & \multirow{2}{*}{$\frac{\operatorname{Mean}\left(\alpha_{1}\right)}{10^{-2}}$} & \multirow{2}{*}{$\frac{\beta_{1}}{10^{-1}}$} & \multirow{2}{*}{$\frac{\beta_{2}}{10^{-2}}$} & \multicolumn{2}{|c|}{ \#Data } & \multicolumn{2}{|c|}{ RMS (TECu) } \\
\hline & & & & & $\mathrm{SZA}<75^{\circ}$ & $\mathrm{SZA} \geq 75^{\circ}$ & $\mathrm{SZA}<75^{\circ}$ & $\mathrm{SZA} \geq 75^{\circ}$ \\
\hline North & $45^{\circ} \leq \mathrm{Ls}<225^{\circ}$ & 3.284 & 2.624 & 1.564 & 159,997 & 983,540 & 0.10 & 0.05 \\
\hline South & $45^{\circ} \leq \mathrm{Ls}<225^{\circ}$ & 2.473 & 5.521 & 0.964 & 217,032 & $1,280,671$ & 0.09 & 0.05 \\
\hline Hem. & $225^{\circ} \leq \mathrm{Ls}<45^{\circ}$ & 3.577 & -0.222 & 2.287 & 220,611 & $1,118,474$ & 0.11 & 0.05 \\
\hline
\end{tabular}

MoMo, model of Mars ionosphere; RMS, root mean square; SZA, solar Zenith angle; TECu, total electron content units; vTEC, vertical total electron content.

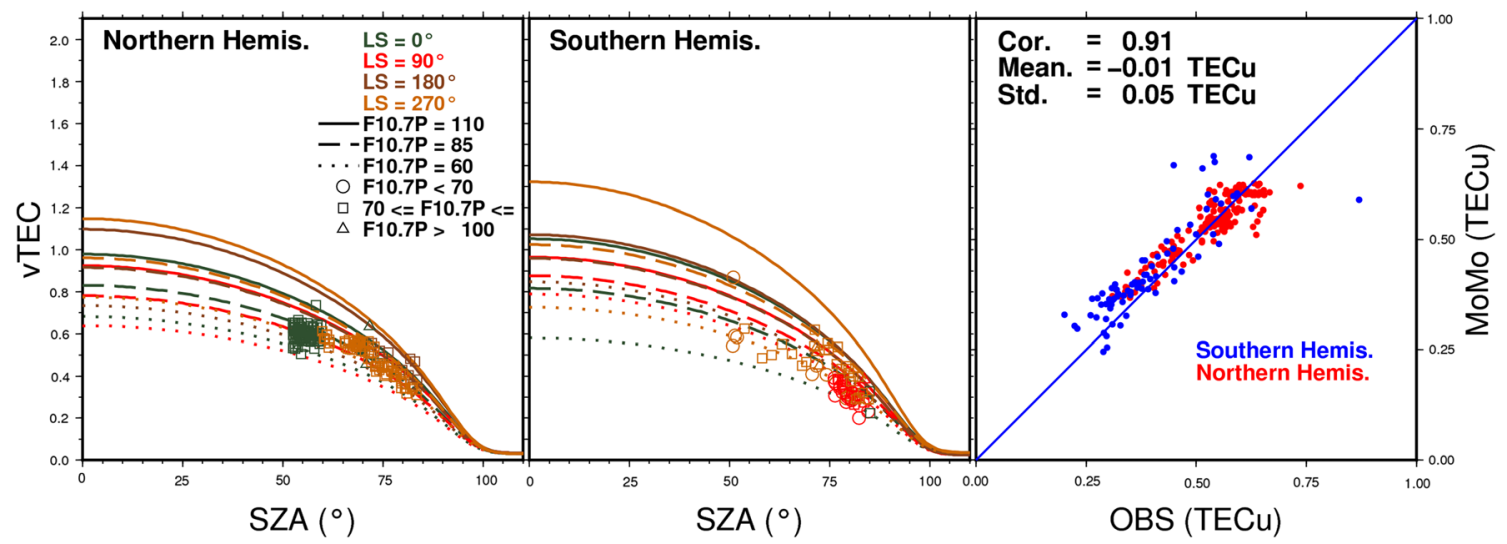

Fig. 5. MoMo empirical model results for the Northern (left) and Southern (middle) hemispheres. The colours correspond to the different seasons (i.e., Ls); the solid, dashed and doted lines represent high, moderate and low solar activity level respectively. Also represented are the radio occultation data (Peter et al., 2014) for different solar activity levels: high (triangle), moderate (square) and low (circle). On the right is the scatter plot showing the MoMo prediction model versus the vTEC from the Mars Express radio occultation data for the two hemispheres.

vTEC at different locations (top Northern hemisphere, bottom Southern Hemisphere corresponding to $20^{\circ} \mathrm{N}$ and $20^{\circ} \mathrm{S}$ respectively), different solar activity level (F10.7P at Earth distance of 70,120 and $170 \mathrm{sfu}$ ) and different seasons. The seasonal differences are given by the two ranges of Ls used to construct the model but also in the $\overline{\mathrm{F} 10.7 \mathrm{P}}$ index (Eq. (1) which is dependent on the heliocentric distance, and consequently on the Ls variations during Mars sidereal year.

At first glance, it appears in Figure 7 that: (1) The maximum of the vTEC (0.9 TECu during low solar activity and $2 \mathrm{TECu}$ during high solar activity) is observed in the Southern hemisphere in Summer. This can be explained by the fact that during this season, the planet is at perihelion, with its rotation axis oriented to receive more solar flux in the South than the North; (2) The night side of the Mars' ionosphere $\left(\mathrm{SZA} \approx 110^{\circ}\right)$ is constant and independent from the solar level activity with a mean value of $0.03 \pm 0.01 \mathrm{TECu}$. This value is consistent with the conclusion from Mendillo et al. (2013); (3) The Northern and Southern hemispheres ( $\mathrm{NH}$ and $\mathrm{SH}$ ) are behaving more or less in the same way with an increase phase in vTEC values from Autumn to Winter and then a decreasing phase from Spring to Summer resulting from the fact that the Mars' ionosphere is mainly driven by the solar flux angle (i.e., SZA), the solar activity and the heliocentric distance. The peaks in Spring/NH and Autumn/SH compared to the next season confirm the recent results of Sánchez-Cano et al. (2018),

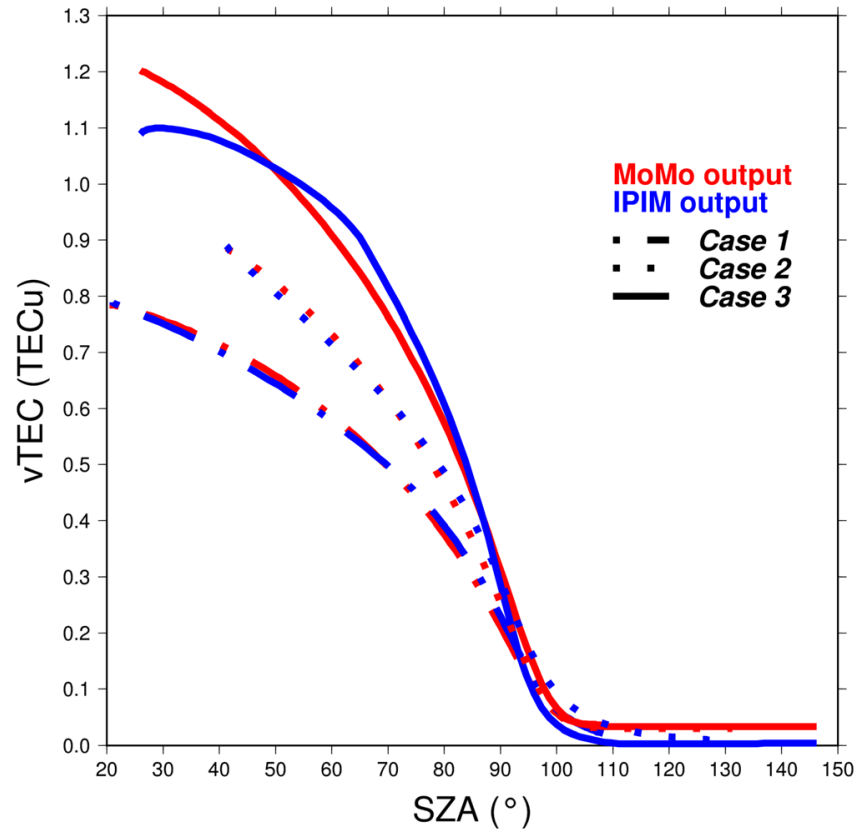

Fig. 6. Comparison between MoMo empirical model and IPIM numerical model. The three cases correspond to different locations, solar activity levels and seasons (see description in the text). In red are the MoMo outputs while in blue are the IPIM outputs. 


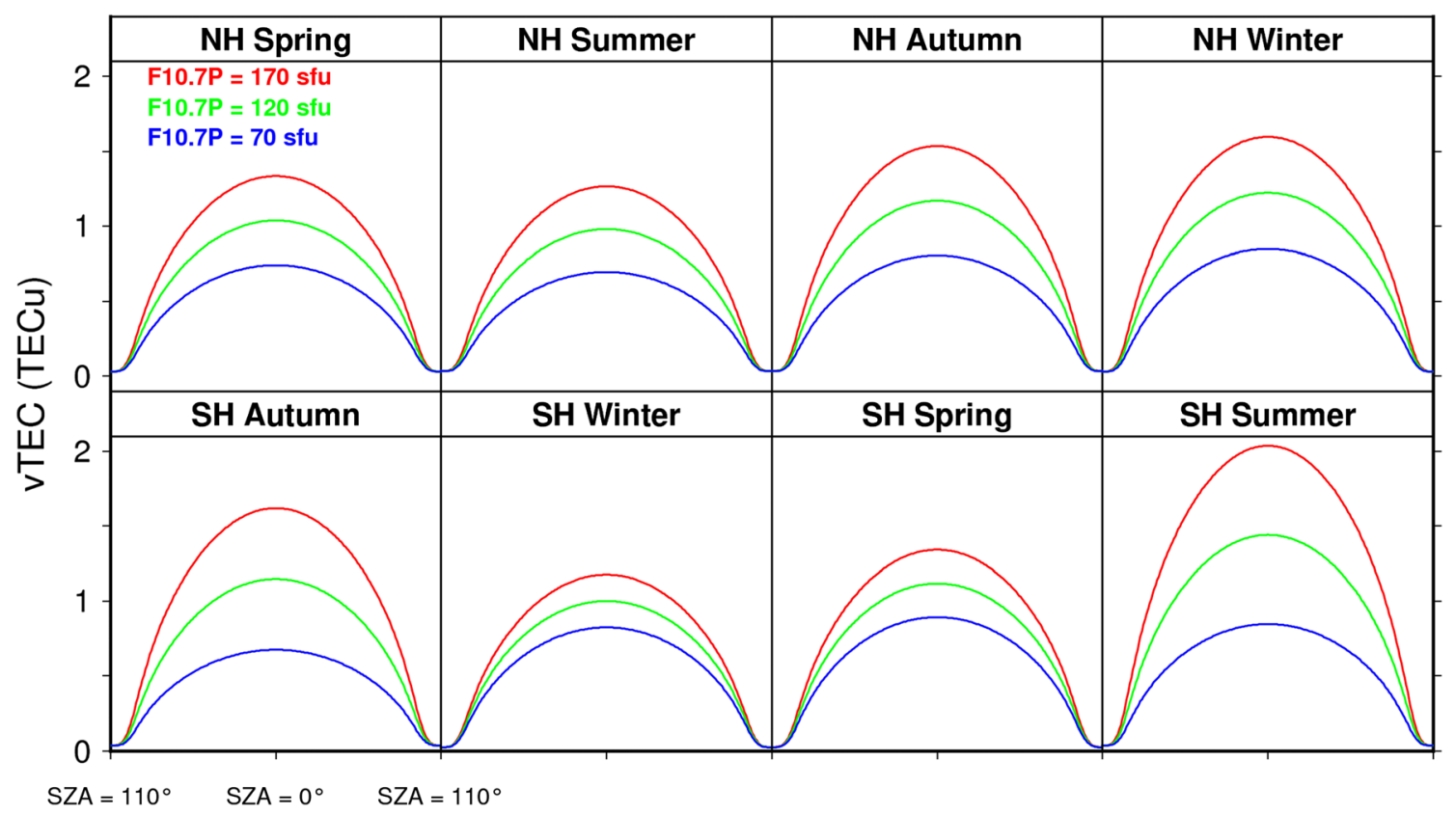

Fig. 7. Seasonal climatological behaviour of the vTEC on Mars for Northern (top, $20^{\circ} \mathrm{N}$ ) and Southern (bottom, $20^{\circ} \mathrm{S}$ ) hemispheres. For each season and hemisphere, each curve corresponds to the daily variation of the vTEC (i.e., SZA from $110^{\circ}$ to $0^{\circ}$ ). The colours correspond to different solar cycle activity levels $(\mathrm{F} 10.7 \mathrm{P}=70,120$ and $170 \mathrm{sfu})$.

who identified a coupling between the lower and upper atmospheres for this range of Ls. The authors concluded that these peaks in the vTEC at these periods are due to an increase in the thermospheric density and changes in ion composition.

Consequently, MoMo shows a Mars' ionosphere variability mainly driven by the solar illumination, activity, and the seasons as expected, with amplitude variations of the vTEC over an entire day lower than $\sim 2 \mathrm{TECu}$.

\subsection{Application to radio-science experiments}

MoMo is now used to estimate the impact of the ionosphere on radio-science experiments between Mars surface assets (e.g., lander, rover, ...) and Mars orbiters or Earth antennas. For that purpose, we produce vTEC maps for Mars with MoMo. Four of those maps, one per season, are shown in Figure 8 for a specific case of noon local time at the meridian origin with a maximum solar activity level of 170 sfu at $1 \mathrm{AU}$.

These maps are then employed to estimate the slant TEC (sTEC, see Fig. 9) in the line of sight of an external object, and to quantify the impact on different wave propagation parameters: phase delay, and Doppler shift. Different radio frequencies from UHF to X-band are used nowadays for Mars for telecommunications and radio-science experiments. Communications between surface assets and Mars orbiters are commonly performed in UHF, while direct-to-Earth radio tracking is now performed in X-band (S-band was used for Viking landers). In both cases, the electromagnetic waves interact with the sTEC present in the Mars' ionosphere.

We consider two hypothetical surface assets positioned at $\mathrm{S} 10^{\circ}$ and $\mathrm{N} 10^{\circ}$ in latitudes and $0^{\circ}$ in longitude (see crosses in Fig. 8). The transmitting/receiving antennas on Earth (or on-board a Mars orbiting spacecraft) are assumed to be at different elevation angles seen from the asset: $20^{\circ}$ and $55^{\circ}$ which correspond to the typical elevation range for present and future radio-science operation of RISE (Folkner et al., 2018) and LaRa (Dehant et al., 2019). We also consider an elevation angle of $90^{\circ}$ (i.e., at the zenith of the asset). The azimuth of the external object is chosen to be $90^{\circ} \mathrm{E}$, i.e., the asset Eastern direction. Only the winter solstice $\left(\mathrm{Ls}=270^{\circ}\right)$ is considered when the vTEC values are maximum. Additionally, the solar activity level is fixed to be in moderate phase $(\mathrm{F} 10.7 \mathrm{P}=120 \mathrm{sfu})$. The frequencies considered are within UHF, S- and X-bands (0.4, 2.0 and 8.0 GHz, respectively). The vTEC from MoMo is projected into slant TEC (sTEC) along the line-of-sight (LOS) at the Ionospheric Pierce Point (IPP) considering a thin shell layer at $140 \mathrm{~km}$ altitude corresponding to the expected altitude of the maximum electron density (Morel et al., 2004, Fig. 8).

Finally the phase delay is estimated (i.e., time delay of the phase, see Tables 2 and 3 in Ho et al., 2002) in meters by using the relation $I=\frac{40.3 \times \mathrm{sTEC} \times 10^{16}}{f^{2}}$ with $f$ the frequency considered. We also estimate the instant Doppler shift due to the Mars' ionosphere TEC change defines as $\Delta f_{\text {iono }}=\frac{40.3}{c \times f} \frac{\mathrm{d}\left(\mathrm{sTEC} \times 10^{16}\right)}{\mathrm{d} t}$ expressed in $\mathrm{Hz}$ ( $\mathrm{mHz}$ is used here) with $c$ the speed of light. Finally, the velocity change due to the Mars' Ionosphere is obtained using $\Delta v_{\text {iono }}=\frac{c \times \Delta f_{\text {inoo }}}{2 \times f}$ expressed in $\mathrm{m} \mathrm{s}^{-1}\left(\mathrm{~mm} \mathrm{~s}^{-1}\right.$ in this study) and assuming a two-way radio-link. These different quantities are given with respect to the Solar Local Time (SLT) at the asset location.

As shown in Figure 10, the maximum phase delay is obtained at 12:20 SLT with a stronger effect at lower elevation and for an asset situated in the Southern hemisphere. In that 

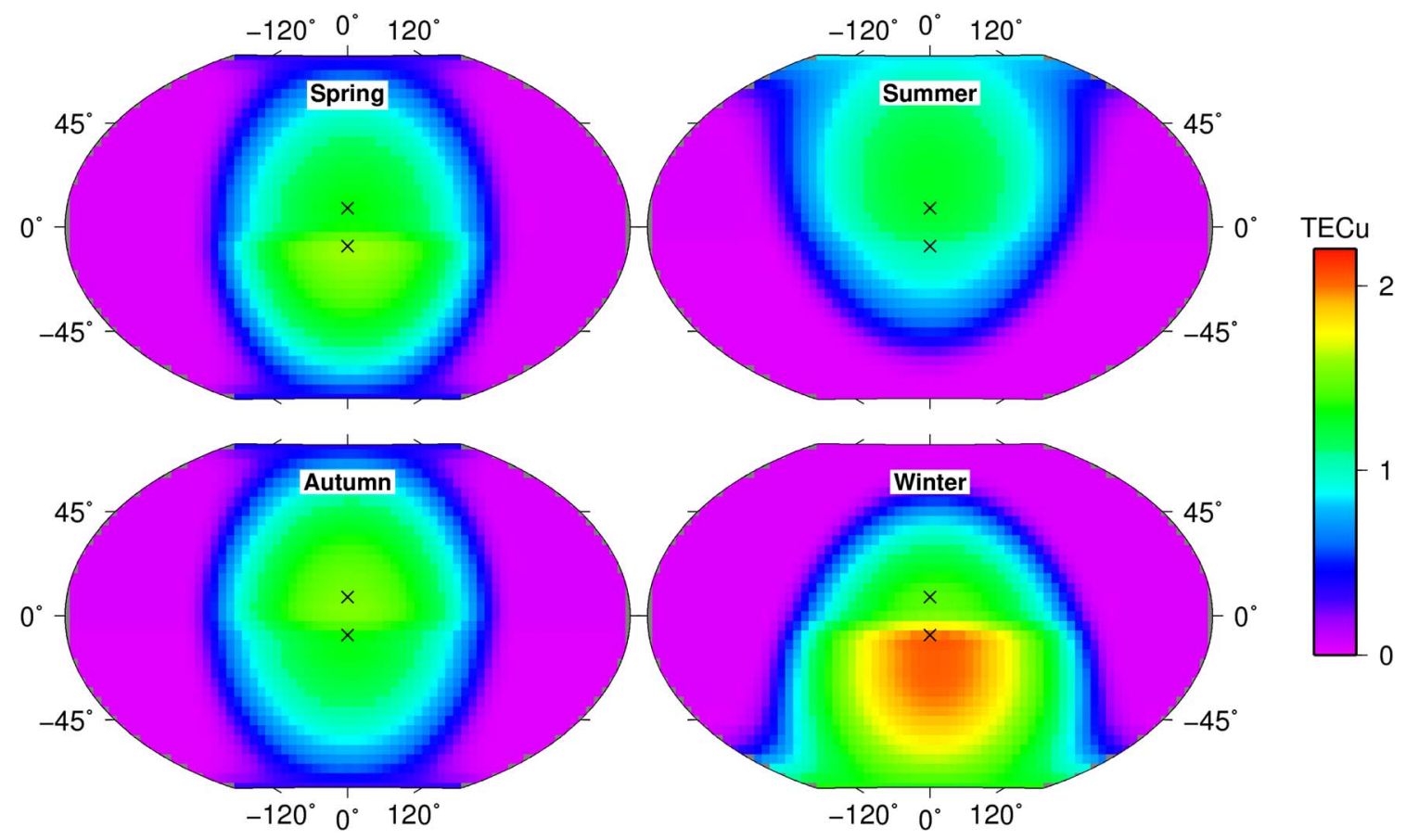

Fig. 8. Global maps of Mars vTEC. The different maps correspond to the different outputs of the MoMo model for different seasons (in the North hemisphere) at local noon at the meridian origin. The F10.7P is fixed for a high solar activity level (170 sfu) corresponding to $\overline{\text { F10.7P }}$ of $70 \mathrm{sfu}$ for spring, $61 \mathrm{sfu}$ for summer, 79 sfu for autumn and 88 sfu for winter. The black crosses are the location of two assets on the Mars surface $\left(\mathrm{N} 10^{\circ}\right.$ and $\mathrm{S} 10^{\circ}$ in latitude; $0^{\circ}$ in longitude) used in Figures 9 and 10.

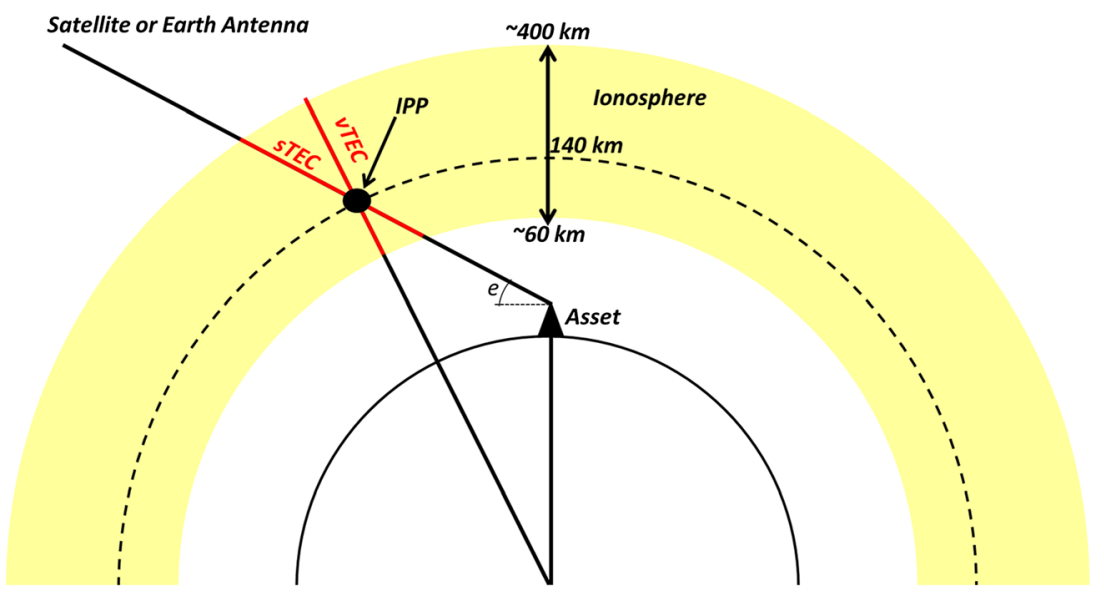

Fig. 9. Projection used to retrieve the sTEC in a line-of-sight from the MoMo vTEC predictions. IPP stands for Ionospheric Pierce Point. $e$ is the elevation angle of the external object with respect to the asset.

case, the values in phase delay reach more than $8 \mathrm{~m}$ in UHF, $32 \mathrm{~cm}$ in S-band and $2 \mathrm{~cm}$ in X-band. At $90^{\circ}$ of elevation (i.e., the Earth or the satellite is at the zenith of the asset) the effect decreases to $3 \mathrm{~m}, 11 \mathrm{~cm}$ and $<0.7 \mathrm{~cm}$ in the Northern hemisphere. Mars ephemeris is mainly constrained by the range measurements of in-situ spacecraft, including those acquired in the late seventies by the Viking landers 1 and 2 . Together, these two landers provided about 1000 range data points in S-band (e.g., Kuchynka et al., 2014), which must be affected by the Martian ionosphere at the tens of centimetre level. This is only 3-10 times below the current accuracy of the ephemeris of Mars, suggesting that one could use MoMo to correct those data when producing the new solution of the Mars trajectory.

The effect on the Doppler measurements is maximum when the TEC suddenly varies. This appends twice per day (see right panels of Fig. 10) during local sunrise and sunset (around 06:00 and 18:45 SLT). The maximum shift is of the order of $\pm 1 \mathrm{mHz}$ (corresponding to $\pm 3.6 \times 10^{-1} \mathrm{~mm} \mathrm{~s}^{-1}$ in velocity change) in UHF, $\pm 2 \times 10^{-1} \mathrm{mHz}\left( \pm 1.5 \times 10^{-2} \mathrm{~mm} \mathrm{~s}^{-1}\right)$ in S-band and $\pm 5 \times 10^{-2} \mathrm{mHz}\left( \pm 1.0 \times 10^{-3} \mathrm{~mm} \mathrm{~s}^{-1}\right)$ in X-band when considering $20^{\circ}$ elevation with respect to the asset. 

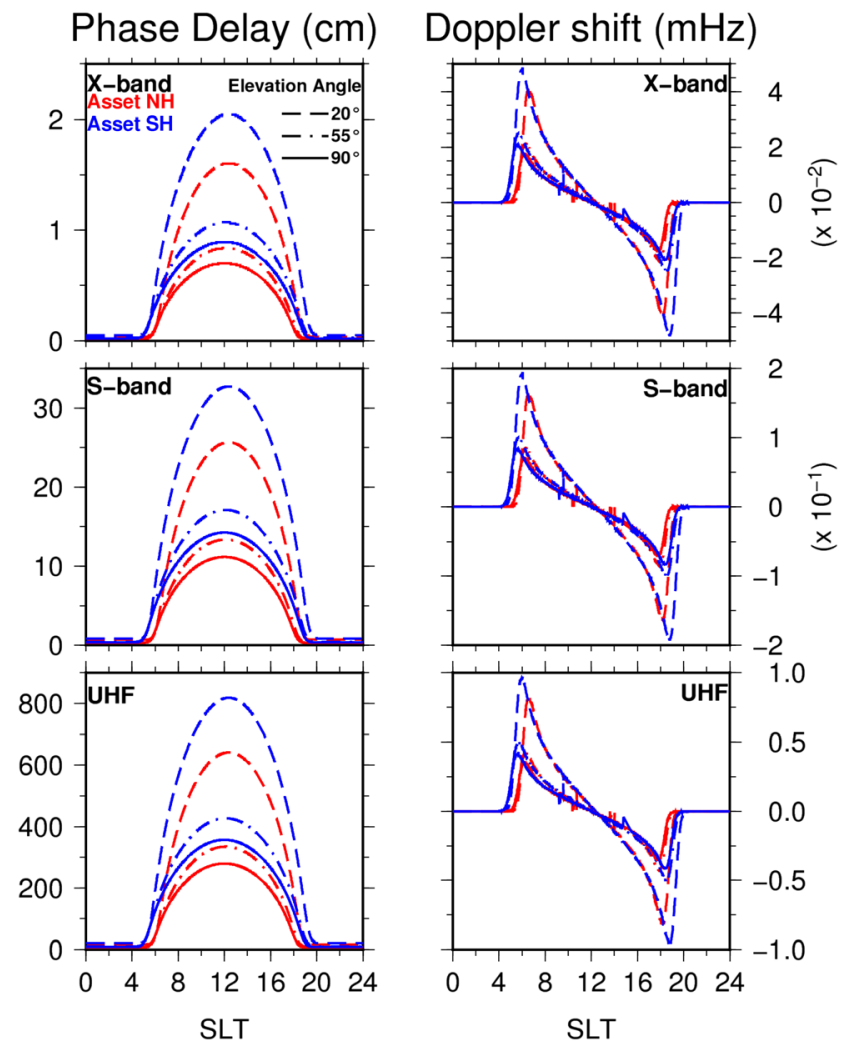

Fig. 10. Effect of the Mars' ionosphere on radio wave propagation. Effect on UHF (0.4 GHz, bottom), S-band (2 GHz, middle) and $\mathrm{X}$-band ( $8 \mathrm{GHz}$, top) radio signals. Left: effect on phase delay in centimetres; Right: impact on instant Doppler shift in $\mathrm{mHz}$ (assuming $\mathrm{d} t=1 \mathrm{~s})$. The red curves correspond to an asset situated in the Northern Hemisphere $\left(\mathrm{E} 0^{\circ}, \mathrm{N} 10^{\circ}\right)$ while the blue curves correspond to the one situated in the Southern Hemisphere $\left(\mathrm{E} 0^{\circ}, \mathrm{S}_{10}{ }^{\circ}\right)$. The bold, dashed-dots and dashed lines correspond to a LOS elevation of $90^{\circ}, 55^{\circ}$ and $20^{\circ}$ respectively (see $e$ the elevation on Fig. 9). The solar activity level is fixed at F10.7P $=120$ sfu (moderate solar activity, see Fig. 1).

Figure 10 shows the seasonal variations of the Mars' ionosphere contribution to the Doppler measurements of an asset located at $\left(\mathrm{E}^{\circ}, \mathrm{N} 10^{\circ}\right)$ and $\left(\mathrm{E} 0^{\circ}, \mathrm{S}^{\circ} 0^{\circ}\right)$. The computation is systematically performed at 06:00 SLT for a signal LOS elevation angle of $20^{\circ}$ above the asset. The solar activity level is maintained constant $(\mathrm{F} 10.7 \mathrm{P}=120 \mathrm{sfu})$, although two periods are distinguished to account for the variations in the thermospheric reservoir between summer and winter (see Table 1). This change is responsible for the periodic signal clearly shown on Figure 10. Modelling such a seasonal signal can be of great importance for radio-science experiments from a lander on Mars as their main scientific objective is the accurate determination of the seasonal variations of Mars rotation rate and spin axis orientation variations called nutations (e.g., Folkner et al., 2018). Indeed, the rotation/orientation variations also affect the Doppler measurements with a periodic signature of one Martian year. Therefore, a large ionospheric contribution to the Doppler shift could in turn introduce bias in the rotation/orientation parameter estimates. Our model predicts a maximum ionospheric contribution at $0.05 \mathrm{mHz}$ level (i.e., $0.001 \mathrm{~mm} \mathrm{~s}^{-1}$ ) in
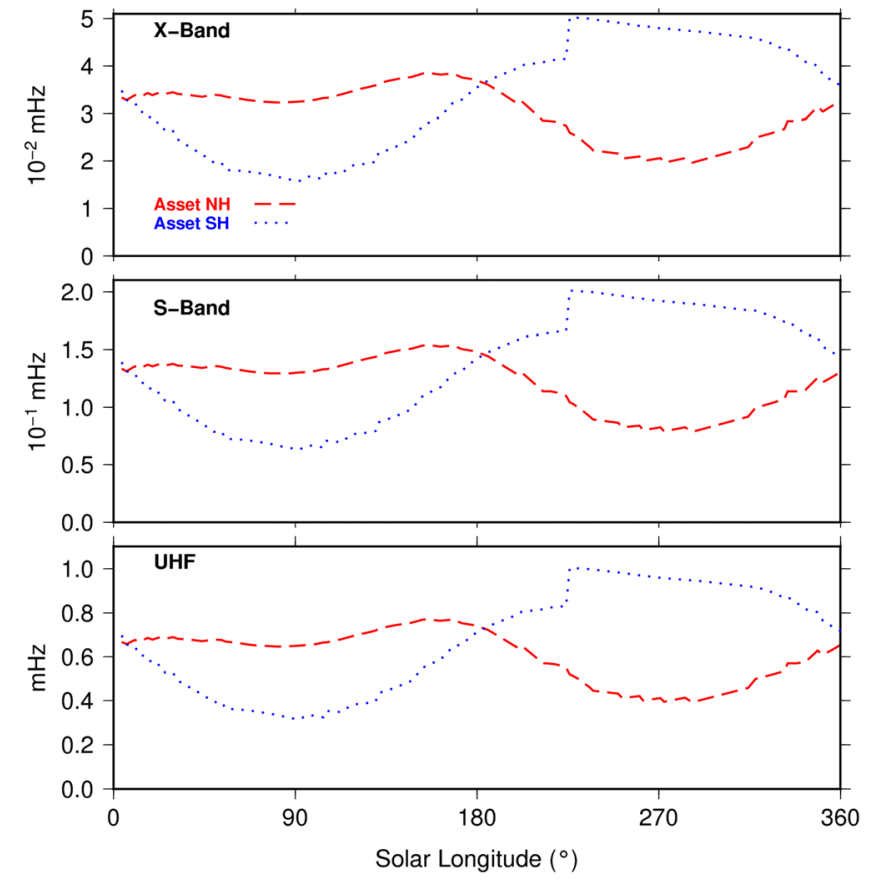

Fig. 11. Ionospheric signature on Doppler shift during a Martian year. Data extracted for different Ls, for a $20^{\circ}$ elevation with respect to the asset at 06:00 SLT. The dashed red and dotted bleu lines correspond to an asset in the Northern and Southern hemispheres respectively. The ionospheric signature on Doppler shift is given for UHF (0.4 GHz, bottom), S-band (2 GHz, middle) and X-band (8 GHz, top) radio signals.

the frequency band of both RISE and LaRa (upper panel of Fig. 11). This is about one order of magnitude below the estimated noise of those instruments, but is of same order of magnitude as the contribution of the liquid core in the Doppler $\left(\sim 10^{-3}-10^{-2} \mathrm{~mm} \mathrm{~s}^{-1}\right.$, Yseboodt et al., 2017). Consequently, the predictions made with MoMo suggests that the radio-science teams will have to either correct their data using our model for instance or adapt the mission programmatic to avoid operating during sunrise and sunset when the TEC rapidly varies.

\section{Conclusion}

We have developed a new empirical model of the Mars Total Electron Content (TEC) called MoMo (available at https://lara.oma.be/marsatmo/iono/momo.html). The model provides values for the vertical TEC (vTEC) for a given solar zenith angle, solar activity, solar longitude Ls in the two Mars hemispheres. The model has been validated with external radio occultation data for high SZA and with the IPIM (IRAP Plasmasphere Ionosphere Model) physical complex model for low SZA. One of the main motivations for this paper was to provide Mars ionosphere corrections for radio-science experiments. We showed that, even if the expected noise of the radio-science instruments is large compare to the Mars ionospheric contribution, it is recommended to correct for this contribution, as its seasonal variations are of the same periods as those of the geophysical parameters determined by the 
experiments. It is advised to apply ionospheric corrections even during moderate solar activity level, above all for long term studies (i.e., more than one Mars sidereal year), such as those aiming at studying the deep interior of the planet. The model provides key radio-science quantities like phase delay and Doppler shift, which can be used to calibrate radio science data like those acquired by RISE on the ongoing InSight mission, by LaRa on the future mission ExoMars 2020 mission, or by historical lander missions (Viking, Pathfinder, MER). In particular, the Mars ephemeris calculations could certainly benefit from the calibration using MOMO of the S-band Viking landers ranging data.

Acknowledgements. This work has been financially supported by the Solar and Terrestrial Centre of Excellence (STCE, http://www.stce.be/) as well as by the Belgian PRODEX program managed by the European Space Agency (ESA) in collaboration with the Belgian Federal Science Policy Office (BELSPO). Also, support from the ESA-ESTEC Faculty is acknowledged. We are grateful for the providers of the tools and findings from SPICE or NAIF/PDS resources, and of the teams that provided the data used to make SPICE kernels. The ensemble of the pictures is produce using the Generic Mapping Tool (GMT, Wessel et al., 2013). We also thank ESA for providing the TEC data set from MARSIS (ftp:// psa.esac.esa.int/) and the NGDC/NOAA for providing the F10.7 data (ftp://ftp.ngdc.noaa.gov). Finally the authors would like to highlight the Rob Lillis from UC Berkeley Space Sciences Laboratory and the anonymous person for their constructive review which clearly contributed to the improvement of the paper. The editor thanks Robert Lillis and an anonymous referee for their assistance in evaluating this paper.

\section{References}

Acton C, Bachman N, Semenov B, Wright E. 2018. A look towards the future in the handling of space science mission geometry. Planet Space Sci 150: 9-12. DOI: 10.1016/j.pss.2017.02.013.

Acton CH Jr. 1996. Ancillary data services of NASA's navigation and ancillary information facility. Planet Space Sci 44(1): 65-70.

Acuña MH, Connerney JEP, Wasilewski P, Lin RP, Mitchell D, Anderson KA, Carlson CW, McFadden J, Rème H, Mazelle C, Vignes D. 2001. Magnetic field of Mars: Summary of results from the aerobraking and mapping orbits. J Geophys Res Planet 106 (E10): 23403-23417. DOI: 10.1029/2000JE001404.

Bergeot N, Tsagouri I, Bruyninx C, Legrand J, Chevalier JM, Defraigne P, Baire Q, Pottiaux E. 2013. The influence of space weather on ionospheric total electron content during the 23rd solar cycle. J Space Weather Space Clim 3: A25. DOI: 10.1051/swsc/ 2013047.

Bilitza D, McKinnell LA, Reinisch B, Fuller-Rowell T, Bilitza D, McKinnell LA, Reinisch B, Fuller-Rowell T. 2011. The international reference ionosphere today and in the future. J Geodesy $\mathbf{8 5}$ (12): 909-920. DOI: 10.1007/s00190-010-0427-x.

Chapman S. 1931. The absorption and dissociative or ionizing effect of monochromatic radiation in an atmosphere on a rotating earth. Proc Phys Soc 43(1): 26. DOI: 10.1088/0959-5309/43/1/305.

Covington AE. 1969. Solar Radio Emission at $10.7 \mathrm{~cm}, 1947-1968$. J R Astron Soc Can 63: 125-132.
Dehant V, Folkner W, Renotte E, Orban D, Asmar S, Balmino G, Barriot JP, Benoist J, Biancale R, Biele J, Budnik F. 2009. Lander radioscience for obtaining the rotation and orientation of Mars. Planet Space Sci 57(8-9): 1050-1067. DOI: 10.1016/j.pss.2008. 08.009.

Dehant V, Le Maistre S, Rivoldini A, Yseboodt M, Rosenblatt P, Van Hoolst T, Mitrovic M, Karatekin Ö, Marty JC, Chicarro A. 2011. Revealing Mars' deep interior: Future geodesy missions using radio links between landers, orbiters, and the Earth. Planet Space Sci 59(10): 1069-1081. DOI: 10.1016/j.pss.2010. 03.014

Dehant V, Le Maistre S, Balanda RM, Bergeot N, Karatekin O, et al. 2019. The radio-science LaRa instrument onboard ExoMars 2020 to investigate the rotation and interior of Mars. Planet. Space Sci. Accepted for Publication.

Flynn CL, Vogt MF, Withers P, Andersson L, England S, Liu G. 2017. MAVEN observations of the effects of crustal magnetic fields on electron density and temperature in the Martian dayside ionosphere. Geophys Res Lett 44(21): 10812-10821. DOI: 10.1002/ 2017 GL075367.

Folkner WM, Dehant V, Le Maistre S, Yseboodt M, Rivoldini A, Van Hoolst T, Asmar SW, Golombek MP. 2018. The rotation and interior structure experiment on the InSight mission to Mars. Space Sci Rev 214(5): 100. DOI: 10.1007/s11214-018-0530-5.

Grima C., Kofman W. 2008. MARSIS derived enhanced ionospheric calibration data. Technical Report No 21646/08/NL/NR, European Space Agency 3, pp. 1-10.

Ho C, Golshan N, Kliore A. 2002. Radio wave propagation handbook for communication on and around Mars, Technical Report 02-5, Jet Propulsion Laboratory, Pasadena, CA.

Klobuchar JA, Parkinson BW, Spilker JJ. 1996. Ionospheric effects in global positioning system: Theory and applications, American Institute of Aeronautics and Astronautics, Washington, DC. Google Scholar.

Kuchynka P, Folkner WM, Konopliv AS, Parker TJ, Park RS, Le Maistre S, Dehant V. 2014. New constraints on Mars rotation determined from radiometric tracking of the Opportunity Mars Exploration Rover. Icarus 229: 340-347. DOI: 10.1016/j.icarus. 2013.11.015.

Lillis RJ, Brain DA, England SL, Withers P, Fillingim MO, Safaeinili A. 2010. Total electron content in the Mars ionosphere: Temporal studies and dependence on solar EUV flux. J Geophys Res Space Phys 115, A11314. DOI: 10.1029/2010JA015698.

Liu L, Chen Y. 2009. Statistical analysis of solar activity variations of total electron content derived at Jet Propulsion Laboratory from GPS observations. J Geophys Res Space Phys 114, A10311. DOI: 10.1029/2009JA014533.

Liu L, Wan W, Ning B, Pirog OM, Kurkin VI. 2006. Solar activity variations of the ionospheric peak electron density. J Geophys Res 111(8): A08304. DOI: 10.1029/2006JA011598.

Marchaudon A, Blelly PL. 2015. A new interhemispheric 16-moment model of the plasmasphere-ionosphere system: IPIM. $J$ Geophys Res Space Phys 120(7): 5728-5745. DOI: 10.1002/2015JA021193.

Mendillo M, Marusiak AG, Withers P, Morgan D, Gurnett D. 2013. A new semiempirical model of the peak electron density of the Martian ionosphere. Geophys Res Lett 40(20): 5361-5365. DOI: 10.1002/2013GL057631.

Mendillo M, Narvaez C, Trovato J, Withers P, Mayyasi M, Morgan D, Kopf A, Gurnett D, Němec F, Campbell B. 2018. Mars Initial Reference Ionosphere (MIRI) model: Updates and validations using MAVEN, MEX, and MRO data sets. J Geophys Res Space Phys 123(7): 5674-5683. DOI: 10.1029/ 2018JA025263. 
Morel L, Witasse O, Warnant R, Cerisier JC, Blelly PL, Lilensten J. 2004. Diagnostic of the dayside ionosphere of Mars using the Total Electron Content measurement by the NEIGE/Netlander experiment: An assessment study. Planet Space Sci 52(7): 603-611.

Morgan DD, Witasse O, Nielsen E, Gurnett DA, Duru F, Kirchner DL. 2013. The processing of electron density profiles from the Mars Express MARSIS topside sounder. Radio Sci 48(3): 197-207. DOI: 10.1002/rds.20023.

Mouginot J, Kofman W, Safaeinili A, Hérique A. 2008. Correction of the ionospheric distortion on the MARSIS surface sounding echoes. Planet Space Sci 56(7): 917-926. DOI: 10.1016/j. pss.2008.01.010.

Pätzold M, Neubauer FM, Carone L, Hagermann A, Stanzel C, Häusler B, Remus S, Selle J, Hagl D, Hinson DP, Simpson RA. 2004. MaRS: Mars express orbiter radio science. In: Mars Express: The Scientific Payload, ESA Publications Division 1240, pp. 141-163.

Peter K, Pätzold M, Molina-Cuberos G, Witasse O, GonzálezGalindo F, Withers $\mathrm{P}$, Bird MK, Häusler B, Hinson DP, Tellmann S, Tyler GL. 2014. The dayside ionospheres of Mars and Venus: Comparing a one-dimensional photochemical model with MaRS (Mars Express) and VeRa (Venus Express) observations. Icarus 233: 66-82. DOI: 10.1016/j.icarus.2014.01.028.

Safaeinili A, Kofman W, Mouginot J, Gim Y, Herique A, Ivanov AB, Plaut JJ, Picardi G. 2007. Estimation of the total electron content of the Martian ionosphere using radar sounder surface echoes. Geophys Res Lett 34(23), L23204. DOI: 10.1029/ 2007 GL032154.

Sánchez-Cano B, Witasse O, Herraiz M, Radicella SM, Bauer J, Blelly PL, Rodríguez-Caderot G. 2012. Retrieval of ionospheric profiles from the Mars Express MARSIS experiment data and comparison with radio occultation data. Geosci Instrum Meth Data Syst 1(1): 77-84. DOI: 10.5194/gi-1-77-2012.

Sánchez-Cano B, Radicella SM, Herraiz M, Witasse O, RodríguezCaderot G. 2013. NeMars: An empirical model of the Martian dayside ionosphere based on Mars Express MARSIS data. Icarus 225(1): 236-247. DOI: 10.1016/j.icarus.2013.03.021.

Sánchez-Cano B, Morgan DD, Witasse O, Radicella SM, Herraiz MF, Orosei R, Cartacci M, Cicchetti A, Noschese R, Kofman W, Grima C. 2015. Total electron content in the Martian atmosphere: A critical assessment of the Mars Express MARSIS data sets. $J$ Geophys Res Space Phys 120(3): 2166-2182. DOI: 10.1002/ 2014JA020630.

Sánchez-Cano B, Lester M, Witasse O, Blelly PL, Indurain M, Cartacci M, González-Galindo F, Vicente-Retortillo Á, Cicchetti A, Noschese R. 2018. Spatial, seasonal and solar cycle variations of the Martian total electron content (TEC): Is the TEC a good tracer for atmospheric cycles? J Geophys Res Planet 123(7): 1746-1759. DOI: 10.1029/2018JE005626.

Smith FL III, Smith C. 1972. Numerical evaluation of Chapman's grazing incidence integral ch $(\mathrm{X}, \chi)$. J Geophys Res 77(19): 3592-3597. DOI: 10.1029/JA077i019p03592.

Wessel P, Smith WH, Scharroo R, Luis J, Wobbe F. 2013. Generic mapping tools: improved version released. Eos Trans Am Geophys Union 94(45): 409-410.

Yseboodt M, Dehant V, Péters MJ. 2017. Signatures of the Martian rotation parameters in the Doppler and range observables. Planet Space Sci 144: 74-88. DOI: 10.1016/j.pss.2017.05.008.

Zuber MT, Lemoine FG, Smith DE, Konopliv AS, Smrekar SE, Asmar SW. 2007. Mars reconnaissance orbiter radio science gravity investigation. J Geophys Res 112(E5), E05S07. DOI: 10.1029/2006je002833.

Cite this article as: Bergeot N, Witasse O, Le Maistre S, Blelly P-L, Kofman W, et al. 2019. MoMo: a new empirical model of the Mars ionospheric total electron content based on Mars Express MARSIS data. J. Space Weather Space Clim. 9, A36. 